\title{
Bonding of an opaque resin to silane-treated porcelain
}

\author{
Rui Li, Ying Chun Sun, Chen Wang and Ping Gao* \\ Department of Prosthodontics, Stomatological Hospital, Tianjin Medical University, Tianjin 300070, \\ China
}

\begin{abstract}
The repair of a fractured porcelain surface with a resin composite was investigated. The effects of applying an opaque resin to porcelain surfaces, which were silanated by a ceramic primer from a repair kit or by an experimental silane coupling agent, were studied. The porcelain surfaces were silanated for $10 \mathrm{sec}$ and $60 \mathrm{~min}$. Three types of adherents were evaluated: opaque resin with light irradiation (OWL), opaque resin without light irradiation (ONL), and no opaque resin (NAO). The shear bond strengths of the resins to the porcelain surfaces were measured before and after thermocycling. The maximum shear bond strength $(6.7 \mathrm{MPa})$ after thermocycling was observed when the silanating period of the ceramic primer was $60 \mathrm{~min}$. The opaque resin had no effect on the bond strength. Moreover, the bond strength obtained with the experimental silane coupling agent was found to be reduced by only $2 \mathrm{MPa}$, even after thermocycling.
\end{abstract}

Keywords: Opaque resin, silane, porcelain, bond strength

\section{Introduction}

Porcelain-fused metal crowns (PFMs) and all-ceramic crowns are commonly used for prosthetics or esthetic restoratives in anterior and molar teeth. The porcelain for PFMs and the porcelain structure of all-ceramic crowns is brittle and can be easily fractured, but a resin composite can be used to effectively repair the fractured porcelain [1-3].

The bonding of a resin composite to a fractured porcelain surface is critical, and the bond strength can be improved by using a silane coupling agent [4]. These agents, organofunctional trialkoxysilane esters, co-polymerize with the $\mathrm{C}-\mathrm{C}$ bonds of the resin cement monomers and bond to the porcelain by means of a siloxane bond. The silane coupling agent most commonly used in clinical dentistry is 3methacryloxypropyltrimethoxysilane (MPTS) [5,6]. Adding an acidic component to the MPTS accelerates the hydrolysis of the methoxy groups and thereby promotes the adsorption of the hydrolysed silane onto the porcelain surface.

Repair kits for restoring fractured porcelain are commercially available $[7,8]$ and consist of acidic etching primers, ceramic primers, opaque resins, and resin composites. It is highly recommended that an adhesive agent be applied onto the porcelain surface which has been silanated by a ceramic primer. The adhesive is then applied to the primed surface under the irradiation of light.

\footnotetext{
*Corresponding author: Ping Gao, Department of Prosthodontics, Stomatological Hospital, Tianjin Medical University, Tianjin 300070, China. Tel.: +86 022 23332034; Fax:+86 022 23332036; E-mail: kqxiufulirui@tijmu.edu.cn.
}

0959-2989/14/\$27.50 @ 2014 - IOS Press and the authors. 
Previous reports [9] indicate that hydrochloric acid accelerates the hydrolysis of the MPTS in solution and thus results in the improved bond durability of the resin to the porcelain. Furthermore, adding 1,2-bis (trimethoxysilyl) ethane (BTS) to the MPTS further increases the bond durability.

The goal of this study was to identify the optimum method for repairing fractured porcelain with a resin composite. The influences of applying an opaque resin onto porcelain surfaces, which were silanated by a ceramic primer from repair kits or by an experimental silane coupling agent, on the shear bond strength of the resin composite was investigated. The effect of the silanation time of the porcelain and light irradiation on the bonding performance was also studied.

\section{Materials and methods}

\subsection{Materials}

Porcelain disks $\left(5 \times 5 \times 2 \mathrm{~mm}^{3}\right.$ ) were made from VITA VMK 95 VITAPAN $^{\circledR}$ A3 (VITA Zahnfabrik, Bad Säckingen, Germany) according to the manufacturer's instructions. The disks were fired in a Heramat C porcelain furnace (Heraeus Kulzer, South Bend, USA).

Clearfil $^{\mathrm{TM}}$ Repair Multi Purpose repair kit (Kuraray, Tokyo, Japan) consisting of Etchant Gel (40\% phosphoric acid), Clearfil Ceramic Primer (containing 10-methacryloyloxydecyl dihydrogen phosphate (MDP) and silane coupler), and Clearfil Opaque (light-curing composite resin) was used. Clearfil Majesty ${ }^{\mathrm{TM}}$ Esthetic A3 (light-curing composite resin) was used as an adherent.

The MPTS (Shin-Etsu Chemical Industry, Tokyo, Japan) and BTS (Tokyo Chemical Industry, Tokyo, Japan) were used to prepare the experimental silane coupling agents. Aqueous hydrochloric acid solution $(0.1 \mathrm{~mol} / \mathrm{L}$, Wako Pure Chemical Industries, Osaka, Japan) was used as an accelerator to induce the hydrolysis of the silane coupling agents.

\subsection{Methods}

\subsubsection{Preparation of the porcelain adherent}

The porcelain disks were embedded in a self-curing pour type resin (Shofu, Tokyo, Japan). These embedded porcelain plates were used as adherents, and the plate surfaces were polished using a sequence of 240-, 600-, and 1,000-grit silicone carbide papers under running water.

\subsubsection{Preparation of the experimental silane coupling agent}

Solutions of two types of experimental silane coupling agents were prepared, i.e., Primer A1 consisting of MPTS only, and Primer A2 consisting of a mixture of MPTS and BTS. The Primer A1 solution was made by dissolving $50 \mathrm{mg}$ MPTS in $1 \mathrm{~mL}$ ethanol. The Primer A2 solution was made by dissolving $50 \mathrm{mg}$ MPTS-BTS silane mixture in $1 \mathrm{~mL}$ ethanol. Three ratios of MPTS-BTS were evaluated: 0,30 , and $50 \mathrm{~mol} \%$ BTS.

The experimental Primer B solutions were prepared as follows. Aqueous hydrochloric acid $(0.01$, 0.05 , and $0.1 \mathrm{~mol} / \mathrm{L}$ ) solutions were prepared by diluting $0.1 \mathrm{~mol} / \mathrm{L}$ hydrochloric acid with distilled and de-ionised water $(\mathrm{pH}=6.0)$. The $\mathrm{pH}$ values of $0.01,0.05$, and $0.1 \mathrm{~mol} / \mathrm{L}$ solutions were $2.31,1.66$, and 1.25, respectively. An experimental Primer B solution was then prepared by diluting each aqueous hydrochloric acid solution by $50 \mathrm{vol} \%$ ethanol. A series of three experimental Primer B solutions were prepared in this manner, and a solution with no added hydrochloric acid was also readied. 


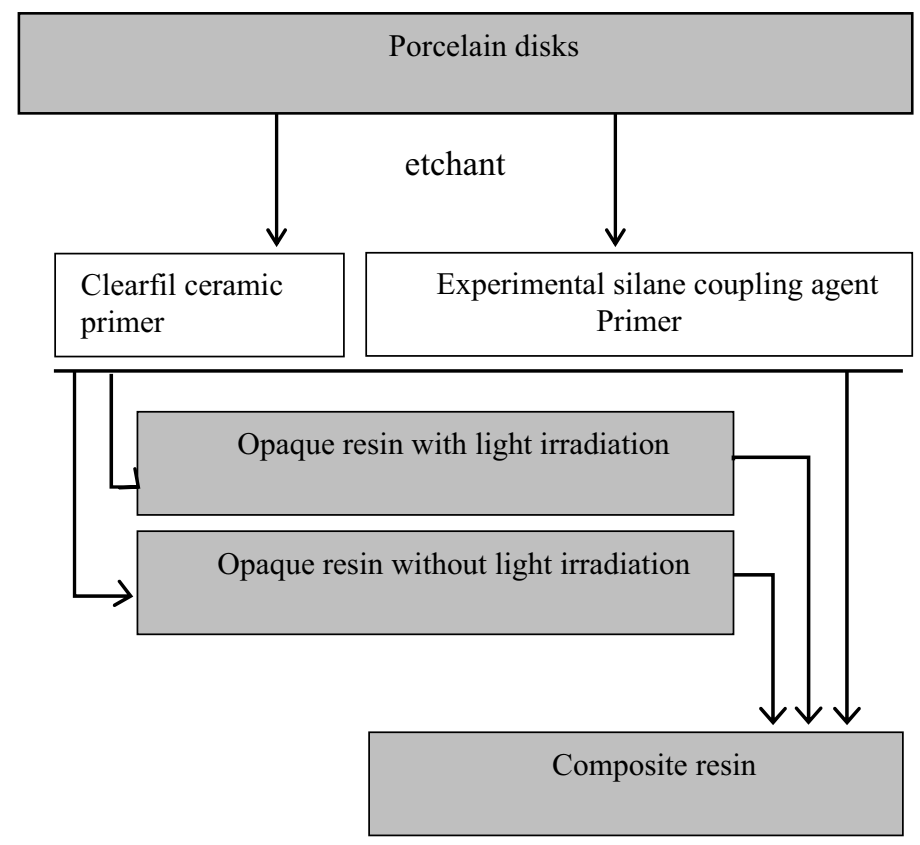

Fig. 1. Diagram of the method.

\subsubsection{Preparation of the adherents}

According to Figure 1, the porcelain surfaces were etched with the Etchant Gel for $5 \mathrm{sec}$, rinsed with water, and dried in air. A single drop of each experimental silane coupling agent (Primer A and Primer B) was placed in a mixing dish and mixed for $20 \mathrm{sec}$. Thereafter, $0.3 \mathrm{mg}$ of the mixed silane coupling agent was applied to the porcelain surfaces. The surfaces were silanated for 1 min to allow the ethanol to evaporate at room temperature $\left(23 \pm 1^{\circ} \mathrm{C}\right)$. The silanated porcelain surfaces were then dried at room temperature for $2 \mathrm{~min}$ and subsequently air-dried for $10 \mathrm{sec}$. The etched porcelain surfaces were then treated with Clearfil Ceramic Primer for $10 \mathrm{sec}$ (as per the manufacturer's instructions) and $60 \mathrm{~min}$ for the comparison.

A silicone ring-mould with a circular hole (internal diameter: $3.2 \mathrm{~mm}$, thickness: $2 \mathrm{~mm}$ ) was placed on the silanated porcelain surface. The silanated adherents were divided into two main experimental groups, i.e., their surfaces were conditioned using the Clearfil Ceramic Primer or an experimental silane coupling agent, and three subgroups as follows.

Group 1: Opaque resin with light irradiation (OWL). The circular hole of the ring mould was filled with the light-curing opaque resin. The sample was then irradiated for $10 \mathrm{sec}$ with visible light using a Curing Light XL 3000 (3M-ESPE, Grafenau, Germany). Thereafter, the mould was filled with the Clearfil Majesty Esthetic light-curing composite resin, and the sample was irradiated for $30 \mathrm{sec}$.

Group 2: Opaque resin without light irradiation (ONL). The circular mould was filled with the opaque resin, followed immediately by the composite resin. The sample was irradiated for $30 \mathrm{sec}$ only after the composite resin was added.

Group 3: No opaque resin (NAO). The ring mould was filled only with the composite resin, and no opaque resin was added. The sample was irradiated for $30 \mathrm{sec}$. 


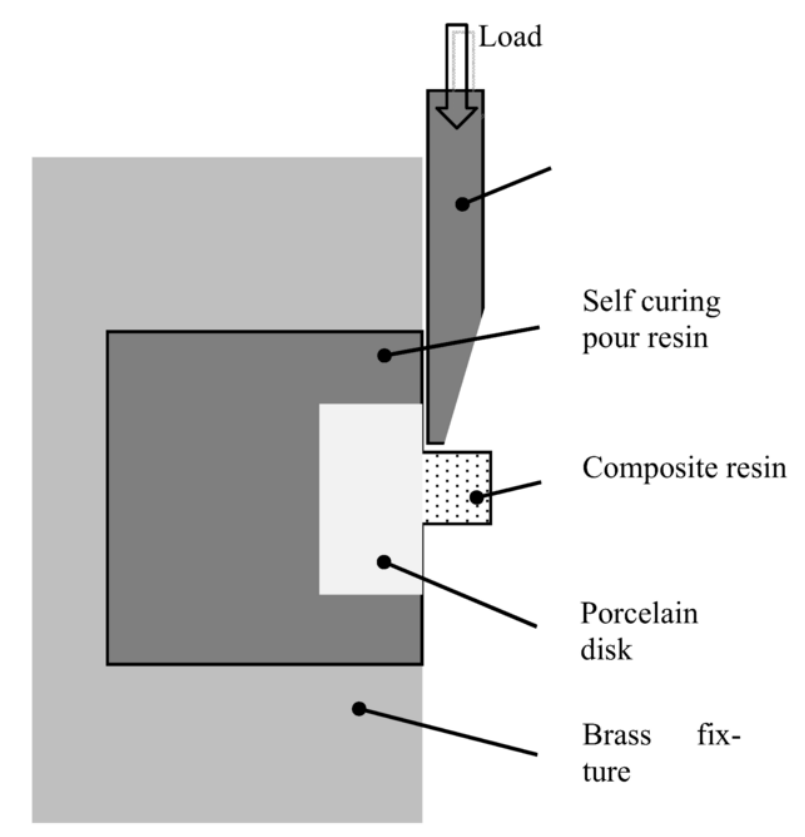

Fig. 2. Cross-sectional illustration of shear bond strength test.

\subsubsection{Measurements of the bond strengths of adherents before and after thermocycling}

The prepared samples were stored in water at $37^{\circ} \mathrm{C}$ for 1 day before the testing. The bonded specimens were divided into two groups: before and after thermocycling. Thermocycling for 5,000 or 10,000 cycles was carried out between 5 and $55^{\circ} \mathrm{C}$ in a water bath. The dwell time in the water bath was $60 \mathrm{sec}$, and the transfer time was $7 \mathrm{sec}$. The shear bond strengths of the composite resin to the silanated porcelain surfaces were measured at a crosshead speed of $1 \mathrm{~mm} / \mathrm{min}$ using a universal testing machine (TG-5KN, Minebea, Nagano, Japan). A cross-sectional view of the shear bond strength test is illustrated in Figure 2. Sixteen specimens were tested for each experimental group.

The average shear bond strength and its standard deviation (SD) were calculated for each group, with and without thermocycling. The results were analysed using two-way analysis of variance (ANOVA) and Scheffé's multiple comparison test. Statistical significance was set at 0.05.

\subsubsection{Determination of the type of fracture mode}

The fracture mode during failure under shear stress was classified as one of three fracture types: interfacial failure at the resin-porcelain interface, mixed failure consisting of interfacial failure and cohesive failure of the porcelain, and cohesive failure of the porcelain [10].

The fracture mode was further analyzed by the complex chi-square $\left(\chi^{2}\right)$ test to determine significant differences between the three types of failures. Statistical significance was set at 0.05 [11].

\section{Results}

Table 1 shows the mean shear bond strength of the composite resin to the porcelain surfaces, which were silanated using the Clearfil Ceramic Primer for $10 \mathrm{sec}$ or $60 \mathrm{~min}$. Data are shown for specimens 
Table 1

Mean shear bond strength of the composite resin to the porcelain surface, which was silanated with the Clearfil Ceramic Primer for $10 \mathrm{sec}$ and $60 \mathrm{~min}$

\begin{tabular}{|c|c|c|c|c|c|}
\hline \multirow{2}{*}{$\begin{array}{l}\text { Experi- } \\
\text { mental } \\
\text { Group }\end{array}$} & \multirow[b]{2}{*}{ Time } & \multicolumn{2}{|c|}{ Mean Shear Bond Strength (MPa) } & \multicolumn{2}{|c|}{ Type of Fracture Mode [1/2/3] } \\
\hline & & $\begin{array}{l}\text { Before Thermo- } \\
\text { cycling }\end{array}$ & After Thermocycling & $\begin{array}{l}\text { Before } \\
\text { Thermocycling }\end{array}$ & $\begin{array}{l}\text { After } \\
\text { Thermocycling }\end{array}$ \\
\hline$\overline{\mathrm{OWL}}$ & & $11.6(3.4)_{\mathrm{a}}^{1}$ & $2.7(1.9)^{2}$ & {$[0 / 0 / 16]_{\mathrm{a}}^{1}$} & {$[15 / 1 / 0]_{\mathrm{a}}^{2}$} \\
\hline ONL & $10 \mathrm{~s}$ & $10.9(2.7)^{1}{ }_{a}^{a}$ & $1.8(0.4)_{\mathrm{a}}^{2}$ & {$[0 / 0 / 16]_{\mathrm{a}}^{1}$} & {$[16 / 0 / 0]_{\mathrm{a}}^{2}$} \\
\hline $\mathrm{NAO}$ & & $10.6(2.3)^{1}{ }_{\mathrm{a}}^{\mathrm{a}}$ & $5.3(1.4)^{2}{ }_{b}^{a}$ & {$[0 / 0 / 16]_{a}^{1{ }^{a}}$} & {$[10 / 5 / 1]_{b}^{2}$} \\
\hline OWL & $60 \mathrm{~min}$ & $11.2(3.0)_{\mathrm{a}}^{1}$ & $4.1(0.8)_{\mathrm{a}}^{2}$ & {$[0 / 0 / 16]_{a}^{1}$} & {$[14 / 2 / 0]_{a}^{2}$} \\
\hline ONL & & $10.6(2.7)^{1}{ }_{a}^{a}$ & $6.7(1.0)^{2}{ }_{b}^{a}$ & {$[0 / 0 / 16]_{a}^{1}$} & {$[9 / 6 / 1]_{b}^{2}$} \\
\hline $\mathrm{NAO}$ & & $10.0(3.3)_{\mathrm{a}}^{\mathrm{a}}$ & $5.1(1.2)^{2} \mathrm{ab}$ & {$[0 / 0 / 16]_{a}^{1}$} & {$[10 / 6 / 0]_{b}^{2}$} \\
\hline
\end{tabular}

Note: ( ): standard deviation. For each horizontal row of mean shear bond strengths: values with different numbered superscripts are statistically different $(\mathrm{P}<0.05)$. For each vertical column of mean shear bond strengths: values with different lettered subscripts are statistically different $(\mathrm{P}<0.05)$. Two-way ANOVA (Scheffé) was used. The sample size for each experimental group was 16. [1/2/3]: 1: Interfacial failure at the resin-porcelain interface; 2: Mixed failure consisting of interfacial failure and cohesive failure of the porcelain; 3: Cohesive failure of the porcelain. For each horizontal row in the type of fracture mode: values with different numbered superscripts are statistically different $(\mathrm{P}<0.05)$. For each vertical column in the type of fracture mode: values with different lettered subscripts are statistically different $(\mathrm{P}<0.05)$. The complex chi-square $\quad\left(\chi^{2}\right)$ test was used. The sample size for each experimental group was 16 .

before and after thermocycling. Prior to thermocycling, the initial bond strengths ranged from 10.0 to 11.6 MPa. No significant differences were observed in the initial mean bond strengths between $10 \mathrm{sec}$ and $60 \mathrm{~min}$ of silanating. Cohesive failure of the porcelain surfaces was observed in all the specimens. Thermocycling caused dramatic decreases in the mean bond strengths of all the specimens, and there were significant differences among all the groups.

For the 10-sec thermocycled groups, the bond strengths of the OWL and ONL groups were significantly lower than that of the NAO group. The failure mode for both groups was interfacial failure of the resin-porcelain interfaces. The failure mode for the NAO samples was mixed failure.

For the 60-min treated groups, the maximum bond strength of $6.7 \mathrm{MPa}$ was obtained for the ONL samples, and the failure mode changed from interfacial to the mixed mode. Significant differences of the bond strengths between the ONL and OWL samples were observed, while no significant differences were observed between the ONL and NAO groups. It could be seen that a longer silanation period improved (with a significant difference) the bond durability of the resin to the porcelain surfaces only for the OWL and ONL groups, i.e., from 2.7 to $4.1 \mathrm{MPa}$ and from 1.8 to $6.7 \mathrm{MPa}$, respectively.

Table 2 shows the effects of thermocycling when different amounts of hydrochloric acid were used in the experimental Primer B. The experimental Primer A1 was applied as a solution and the adherent group of opaque resin with light irradiation (OWL) was used to study the shear bond strength.

Before thermocycling, the addition of hydrochloric acid tended to increase the mean bond strength. Specifically, using 0.01 or $0.05 \mathrm{~mol} / \mathrm{L}$ aqueous hydrochloric acid led to an increase in the mean bond strengths from 6.0 to $19.0 \mathrm{MPa}$ and 6.0 to $19.5 \mathrm{MPa}$, respectively. However, a higher concentration of hydrochloric acid $(0.1 \mathrm{~mol} / \mathrm{L})$ reduced the mean bond strength to $15.7 \mathrm{MPa}$. Thermocycling was found to decrease the mean bond strength of the samples with any hydrochloric acid added. The greatest decrease was observed in the sample containing $0.01 \mathrm{~mol} / \mathrm{L}$ hydrochloric acid, where the mean bond strength dropped from 19.0 to $12.7 \mathrm{MPa}$. In contrast, the addition of $0.05 \mathrm{~mol} / \mathrm{L}$ hydrochloric acid resulted in the mean bond strength of $14.6 \mathrm{MPa}$ after thermocycling.

Table 3 shows the effects of different MPTS-BTS mixture ratios, which were used to prepare the experimental Primer A2 before and after thermocycling. The BTS concentrations were 0,30 , and 50 
Table 2

Effects of different concentrations of aqueous hydrochloric acid used with experimental Primer B on the shear bond strength before and after thermocycling

\begin{tabular}{|c|c|c|c|c|}
\hline \multirow{2}{*}{$\begin{array}{l}\text { Concentra- } \\
\text { tion of } \mathrm{HCl} \\
(\mathrm{mol} / \mathrm{L})\end{array}$} & \multicolumn{2}{|c|}{ Mean Shear Bond Strength (MPa) } & \multicolumn{2}{|c|}{ Type of Fracture Mode [1/2/3] } \\
\hline & $\begin{array}{l}\text { Before } \\
\text { Thermocycling }\end{array}$ & $\begin{array}{l}\text { After } \\
\text { Thermocycling }\end{array}$ & $\begin{array}{l}\text { Before } \\
\text { Thermocycling }\end{array}$ & $\begin{array}{l}\text { After } \\
\text { Thermocycling }\end{array}$ \\
\hline $\begin{array}{l}0 \\
0.01 \\
0.05 \\
0.1 \\
\end{array}$ & $\begin{array}{l}6.0(1.8)^{1}{ }_{\mathrm{a}} \\
19.0(4.2)^{1}{ }_{\mathrm{b}} \\
19.5(3.7)^{1}{ }_{\mathrm{b}} \\
15.7(3.6)^{1}{ }_{\mathrm{c}}\end{array}$ & $\begin{array}{l}1.2(1.5)^{2}{ }_{\mathrm{a}} \\
12.7(3.2)^{2}{ }_{\mathrm{b}, \mathrm{c}} \\
14.6(3.0)^{2}{ }_{\mathrm{b}} \\
10.6(3.5)^{2}{ }_{\mathrm{c}}\end{array}$ & $\begin{array}{l}{[10 / 6 / 0]^{1}{ }_{a}} \\
{[0 / 0 / 16]^{1}{ }_{b}} \\
{[0 / 0 / 16]^{1}{ }_{b}} \\
{[0 / 0 / 16]_{b}^{1}}\end{array}$ & $\begin{array}{l}{[16 / 0 / 0]^{2}{ }_{a}} \\
{[0 / 1 / 15]^{1}{ }_{b}} \\
{[0 / 0 / 16]^{1}{ }_{b}} \\
{[0 / 2 / 14]_{b}^{1}}\end{array}$ \\
\hline
\end{tabular}

Table 3

Effects of the amount of BTS added to the MPTS used in the experimental Primer A2 on the shear bond strength before and after thermocycling

\begin{tabular}{|c|c|c|c|c|}
\hline \multirow{2}{*}{$\begin{array}{l}\text { Amount } \\
\text { of BTS } \\
(\mathrm{mol} \%)\end{array}$} & \multicolumn{2}{|c|}{ Mean Shear Bond Strength (MPa) } & \multicolumn{2}{|c|}{ Type of Fracture Mode [1/2/3] } \\
\hline & $\begin{array}{l}\text { Before } \\
\text { Thermocycling }\end{array}$ & $\begin{array}{l}\text { After } \\
\text { Thermocycling }\end{array}$ & $\begin{array}{l}\text { Before } \\
\text { Thermocycling }\end{array}$ & $\begin{array}{l}\text { After } \\
\text { Thermocycling }\end{array}$ \\
\hline $\begin{array}{l}0 \\
30 \\
50 \\
\end{array}$ & $\begin{array}{l}19.5(3.7)^{1}{ }^{\mathrm{a}} \\
19.8(4.1)^{1}{ }^{\mathrm{a}} \\
16.9(3.5)^{1}{ }_{\mathrm{a}}\end{array}$ & $\begin{array}{l}14.6(3.0)^{2}{ }_{\mathrm{a}, \mathrm{c}} \\
16.5(4.0)^{1}{ }_{\mathrm{b}} \\
13.0(3.8)^{2}{ }_{\mathrm{c}}\end{array}$ & $\begin{array}{l}{[0 / 0 / 16]^{1}} \\
{[0 / 0 / 16]^{1}} \\
{[0 / 0 / 16]_{a}^{1}}\end{array}$ & $\begin{array}{l}{[0 / 0 / 16]_{\mathrm{a}}^{1}} \\
{[0 / 0 / 16]^{1}} \\
{[0 / 1 / 15]_{\mathrm{a}}^{1}}\end{array}$ \\
\hline
\end{tabular}

Table 4

Mean shear bond strength of the composite resin and the porcelain surface, which had been silanated by the experimental silane coupling agent

\begin{tabular}{|c|c|c|c|c|}
\hline \multirow[b]{2}{*}{ Experimental Group } & \multicolumn{4}{|c|}{ Mean Shear Bond Strength (MPa) } \\
\hline & $\begin{array}{l}\text { Before } \\
\text { Thermocycling }\end{array}$ & $\begin{array}{l}\text { After } \\
\text { Thermocycling }\end{array}$ & $\begin{array}{l}\text { Before } \\
\text { Thermocycling }\end{array}$ & $\begin{array}{l}\text { After } \\
\text { Thermocycling }\end{array}$ \\
\hline $\begin{array}{l}\text { OWL } \\
\text { ONL } \\
\text { NAO }\end{array}$ & $\begin{array}{l}19.8(4.1)^{1}{ }^{\mathrm{a}} \\
18.7(3.9)^{1}{ }^{\mathrm{a}} \\
18.5(3.5)^{1}{ }_{\mathrm{a}}\end{array}$ & $\begin{array}{l}16.5(4.0)^{1}{ }_{\mathrm{a}} \\
17.8(3.8)^{1}{ }_{\mathrm{a}} \\
16.2(4.7)^{1}{ }_{\mathrm{a}}\end{array}$ & $\begin{array}{l}{[0 / 0 / 16]^{1}{ }_{\mathrm{a}}} \\
{[0 / 0 / 16]_{\mathrm{a}}^{1}} \\
{[0 / 0 / 16]_{\mathrm{a}}^{1}}\end{array}$ & $\begin{array}{l}{[0 / 0 / 16]^{1}{ }_{\mathrm{a}}} \\
{[0 / 0 / 16]^{1}{ }_{\mathrm{a}}} \\
{[0 / 0 / 16]_{\mathrm{a}}^{1}}\end{array}$ \\
\hline
\end{tabular}

mol\%. The concentration of hydrochloric acid in the experimental Primer B remained at $0.05 \mathrm{~mol} / \mathrm{L}$. The OWL adherent group was used to investigate the shear bond strength.

Before thermocycling, the mean bond strength ranged from 16.9 to $19.8 \mathrm{MPa}$ (showing no significant difference). All of the specimens exhibited cohesive failure. However, after thermocycling, a significant reduction in the mean bond strength of approximately $5 \mathrm{MPa}$ was observed with the use of MPTS. In contrast, the addition of BTS to the MPTS reduced the strength reduction. For example, when $30 \mathrm{~mol} \%$ BTS was added to the primer, the mean bond strength decreased by less than $2 \mathrm{MPa}$.

Table 4 shows the mean shear bond strength of the composite resin to the porcelain surfaces, which were silanated by the experimental silane coupling agent before and after thermocycling. Prior to thermocycling, the initial bond strengths ranged from 18.5 to $19.8 \mathrm{MPa}$ (no significant differences) when the porcelain surface was conditioned by the experimental silane coupling agent. All the specimens failed cohesively. The mean bond strength did not decrease significantly after thermocycling, and all the specimens failed cohesively. 


\section{Discussion}

Manufacturers suggest silanating porcelain surfaces to enhance the bonding of the composite resins to the porcelain surfaces for the repair of fractured porcelain, and then light irradiation should be used to polymerize the opaque resin. MPTS is commonly used as the silane coupling agent, and an organic acid is used as the accelerator [12-14].

In this study, an experimental silane coupling agent was used. It was a mixture of MPTS and BTS. Hydrochloric acid was used as an accelerator for the hydrolysis of the methoxy portions of the functional silicone group. The effects of the opaque resin, irradiating with visible light, and extending the silanating period on the bond strength were all investigated.

Before thermocycling, there were no statistical differences in the mean bond strengths between the experimental groups (Table 1). This is because the porcelain failed cohesively in all specimens.

After thermocycling, the mean bond strength dramatically decreased and the fracture mode changed from cohesive failure of the porcelain to interfacial or mixed failure. The significant diminution in the bond strength can be attributed to a reduced chemisorption of the hydrolysed silane species. This hindrance occurs because the carbonyl portion in the methacryloxy ester group of the methacrylate monomers forms a hydrogen bond with the silanol groups on the porcelain surface [15-17]. Compared with the OWL, the statistically higher bond strengths of the ONL are caused by the differences in the thermal expansion between the porcelain and the opaque resin..

With the exception of the NOA group, extending the silanation period with the ceramic primer from $10 \mathrm{sec}$ to $60 \mathrm{~min}$ improved the bond durability. It takes more than 14 days for the deposited silane to completely saturate and chemisorb onto the silica surface. The increase in the bond strength after 60 min silanation is due to the improved cohesiveness of the adsorbed silane layer at the resin-porcelain interface. The stronger cohesiveness can be attributed to an increase in the amount of chemisorbed hydrolysed silane species. The methoxy portion of the silicone functional group in the MPTS continuously hydrolyses during the $60 \mathrm{~min}$ of silanation. Most of the silane species on the porcelain surface are unhydrolysed after only $10 \mathrm{sec}$ of silanation, and thermocycling reduces the bond strength. This reduction in the bond strength is attributed to the unhydrolysed silane species deposited onto the porcelain surface dispersing and permeating into the applied opaque resin.

Table 2 shows that the addition of hydrochloric acid to the silane solution tended to improve the bond strength. The increases in the mean bond strength, from 6 to approximately $19 \mathrm{MPa}$, were observed when 0.01 or $0.05 \mathrm{~mol} / \mathrm{L}$ hydrochloric acid was used. The improvement stemmed from three sources: 1) the proton, produced by the dissociation of the hydrochloric acid, accelerating the hydrolysis of the methoxy portion in the silicone-functional group in the MPTS, 2) the hydrolysed silane species of the MPTS forming a silane bilayer consisting of a chemisorbed and a physisorbed silane layer on the porcelain surface, and 3) the physisorbed silane species of the MPTS forming a hydrogen bond with the chemisorbed silane species of MPTS, thereby enhancing the bonding of the resin cement at the resin-ceramic interface. Conversely, a further increase in the hydrochloric acid concentration from 0.05 to $0.1 \mathrm{~mol} / \mathrm{L}$ resulted in a decreased mean bond strength. This decrease can be attributed to the production of a high-molecular-weight silane species derived through a condensation reaction between the silanol groups of the hydrolysed MPTS monomer.

Adding BTS to the MPTS decreased the magnitude of the reduction in the mean bond strength, even when thermocycling was applied. Specifically, when $30 \mathrm{~mol} \%$ BTS in the MPTS was used, the reduction in the mean bond strength was less than approximately $2 \mathrm{MPa}$. The BTS improved the bond durability by improving the distribution of thermal stresses, which developed at the resin-ceramic interface during the thermocycling process. 
Table 4 shows that the addition of hydrochloric acid to the silane solution increased the mean bond strength. Cohesive failure of the porcelain was observed with and without thermocycling. There are several reasons for this significant improvement. Firstly, the proton produced by the dissociation of the hydrochloric acid accelerates the hydrolysis of the methoxy functional group in the MPTS [16,17]. The hydrolysed silane species of the MPTS also forms a bilayer consisting of a chemisorbed and a physisorbed silane layer on the porcelain surface [19]. Secondly, the physisorbed silane species of the MPTS, which forms a hydrogen bond with the chemisorbed silane species of the MPTS, enhances the bonding of the resin cement at the resin-porcelain interface [18-21]. The BTS increased the bond durability by distributing the thermal stresses, which developed at the resin-porcelain interface during thermocycling. The addition of BTS to the MPTS enabled a flexible silane bilayer to form on the porcelain surface and decreased the crosslinked density of the vinyl group of the methacryloxy portion in the MPTS species adsorbed onto the porcelain surface. The BTS molecule has two silicon functional groups that interact with the MPTS to form a flexible silane bilayer and does not have a vinyl functional group that would promote radical co-polymerisation with the resin.

\section{Conclusion}

The use of an opaque resin did not affect the bond strength of the resin to the porcelain. Prolonging the silanation period of the ceramic primer from $10 \mathrm{sec}$ to $60 \mathrm{~min}$ increased the bond strength of the resin to the porcelain surface. The 10 -sec time suggested by the manufacturer was too short for significant chemisorption of the MPTS to occur onto the porcelain surface.

The highest bond durability of the resin to a porcelain surface was obtained when the experimental silane coupling agent was used instead of the ceramic primer from the repair kits. The optimal combination was $30 \mathrm{~mol} \%$ BTS in an MPTS-BTS mixture with $0.05 \mathrm{~mol} / \mathrm{L}$ aqueous hydrochloric acid.

\section{Acknowledgement}

This study was financially supported by the Natural Science Foundation of Tianjin, China (12JCYBJC31300).

\section{References}

[1] B. Henriques, S. Gonçalves, D. Soares and F.S. Silva, Shear bond strength comparison between conventional porcelain fused to metal and new functionally graded dental restorations after thermal-mechanical cycling, J. Mech. Behav. Biomed. Mater. 13 (2012), 194-205.

[2] M. Aida, M. Wakami, T. Watanabe, Y. Omura and N. Nishiyama, Effects from applying adhesive agents onto silanated porcelain surface on the resin bond durability, Dent. Mater. J. 3 (2008), 427-432.

[3] M.H. Abd. Wahab, W.Z. Bakar and A. Husein, Different surface preparation techniques of porcelain repaired with composite resin and fracture resistance, J. Conserv. Dent. 14 (2011), 387-390.

[4] M. Aida, N. Tabei, S. Kimoto, H. Tanimura, H. Takahashi, T. Yaguchi and N. Nishiyama, Ceramic bond durability and degradation mechanism of commercial gamma-methacryloxypropyl trimethoxysilane-based ceramic primers, Am. J. Dent. 25 (2012), 231-234.

[5] Y. Taira, M. Sakai and T. Sawase, Effects of primer containing silane and thiophosphate monomers on bonding resin to a leucite-reinforced ceramic, J. Dent. 40 (2012), 353-358.

[6] J. Matinlinna, L.V.J. Lassila, M.O” zcan, A. Yli-Urpo and P.K. Vallittu, An introduction to silanes and their clinical applications in dentistry, Int. J. Prosthodont. 17 (2004), 155-164. 
[7] P.J. Van der Vyver, F.A.de Wet and S.J. Botha, Shear bond strength of five porcelain repair systems on cerec porcelain, outh African Dental Journal 60 (2005), 196-198.

[8] A. Leibrock, M. Degenhart, M. Behr, M. Rosentritt and G. Handel, In vitro study of the effect of thermo- and loadcycling on the bond strength of porcelain repair systems, J. Oral. Rehabil. 26 (1999), 560-568.

[9] R. Li, Development of a ceramic primer with higher bond durability for resin cement, J. Oral. Rehabil. 37 (2010), 560568.

[10] C. Hen, W. Oh and J.R. Williams, Effect of post-silanization drying on the bond strength of composite to ceramic, J. Prosthet. Dent. 91 (2004), 453-458.

[11] C.J. larmour and D.R. Stirrups, An ex vivo assessment of a resin-modified glass ionomer cement in relation to bonding technique, J. Orthod. 28 (2001), 207-210.

[12] D.M. Wolf, K.L. Powers and O' Keefe, Bond strength of composite to porcelain treated with new porcelain repair agents, Dent. Mater. 8 (1992), 158-161.

[13] K. Kamada, K. Yoshida and M. Atsuta, Effect of porcelain surface treatments on the bond of four resin luting agents to a ceramic materal, J. Prosthet. Dent. 79 (1998), 508-513.

[14] M. Aida, T. Hayakawa and K. Mizukawa, Adhesion of composite to porcelain with various surface conditions, J. Prosthet. Dent. 73 (1995), 464-470.

[15] B. Arkles, Applying a silane coupling agent, in: Silane Coupling Agent: Connecting across Boundaries, E. Plueddemann, ed., Gelest, Morrisville, 2006, pp. 19.

[16] J.D. Miller, K. Hoh and H. Ishida, Studies of the simulation of silane coupling agent structures on particulate fillers; the pH effect, Polymer Composites 5 (1984), 18-29.

[17] N. Nishiyama, R. Shick and H. Ishida, Adsorption behavior of a silane coupling agent on colloidal silica studied by gel permeation chromatography, J. Colloid. and Interface Sci. 143 (1991), 146-156.

[18] V.R. Noort, Physical properties, in: Introduction to Dental Materials, 2nd edi., Mosby, West Hollywood (CA), 2003 , pp. 49.

[19] N. Nishiyama, K. Komatsu, K. Fukai and K. Nemoto, Influence of adsorption characteristics of silane on the hydrolytic stability of silane at the silica-matrix interface, Composites 26 (1995), 309-313.

[20] H. Ishida and J.D. Miller, Cyclization of methacrylate-, Polym. Sci. Polym. Phys. Ed. 23 (1985), 2227-2242.

[21] K. Sakanashi and N. Nishiyama, Studies on the treatment of glass surface-treatment of glass surface by methacryloxyalkyl-trimethoxysilanes with different chain lengths and its reinforcement effects, J. J. Dent. Mater. 3 (1984), $284-294$. 